\title{
11
}

\section{Faculty Development at Small and Liberal Arts Colleges}

\author{
Kim M. Mooney \\ St. Lawrence University \\ Michael Reder \\ Connecticut College
}

The notable growth of faculty development programs and centers at small institutions warrants attention before their next stages of growth. We aim to capture and convey the central issues coalescing around the professionalization of teaching and learning activities and the work of faculty developers at small colleges. While this descriptive review draws direct comparisons to other types of institutions, particularly large research and comprehensive universities that serve as the norm for our profession's faculty development practices, its main purpose is to address the distinctive characteristics of professional development at small colleges in general and liberal arts colleges in particular. Toward this end, we identify and explore four key issues: the characteristics and traditions related to teaching and learning in these institutional settings; the models and structures for teaching and learning programs at such colleges; the distinctive components of successful faculty development work at such institutions; and the broad applications that small college programs have for other institutional types and the future of our profession.

$\mathrm{T}$

he past seven years have witnessed tremendous growth in the professionalization of faculty development at small colleges, particularly at residential liberal arts colleges. We have seen steady growth since 1999 in many relevant areas: small college membership and attendance at the annual conference of the Professional and Organizational Development Network in Higher Education (POD); the number of conference sessions about small college is- 
sues at this conference (recently close to a dozen); the creation of a formal Small College Committee within the POD governance system; and the number of subscribers to the small college listserv, from just over a few dozen members in fall 2001, to almost 100 members in 2004, to more than 160 members in fall 2006. In 2002, the conference officially inaugurated the position of small college conference coordinator. According to POD membership data from 2006 broken down by Carnegie institutional classifications, almost $80 \%$ of doctoral-extensive (119 out of 151 ) institutions are POD members, but for baccalaureate liberal arts and baccalaureate general, the percentages are still relatively low: fewer than $15 \%$ (34 out of 228 ) and $10 \%$ (32 out of 321 ), respectively. Therefore, the growth potential among small baccalaureate institutions, in terms of both percentages and raw numbers, is tremendous.

Emerging issues in and changing models of higher education have led to a growing need for faculty development at colleges and universities, including liberal arts colleges (Lieberman \& Guskin, 2003; Mooney, Reder, \& Holmgren, 2005). Yet with a few notable exceptions (e.g., Sorcinelli, Austin, Eddy, \& Beach, 2006), the professional literature has not directly addressed the professional experiences, programming goals, and other potentially distinctive issues and concerns of faculty development at liberal arts and other small colleges. The relatively low representation of small college faculty developers in recent surveys about practices and support structures at different institutional types (Brinko, Atkins, \& Miller, 2005; Frantz, Beebe, Horvath, Canales, \& Swee, 2005; Mullinix \& Chism, 2005) is most likely due to the still relatively small cohort size. Nevertheless, as faculty development programs and centers continue to proliferate at smaller institutions, identifying the distinctive features of this work and the elements of successful small college programs should prove helpful during the next growth stages of this professional sector.

\section{The Characteristics of Teaching and Learning at Small Colleges}

We are often asked by our colleagues exactly just what the term small college means. With no litmus test for "small," those faculty developers interested in the small college movement and the POD Small College Committee have traditionally self-identified. That said, these self-identifiers generally work at institutions with at least some of these characteristics: the institution is predominantly undergraduate and teaching is a main mission; it has a faculty under 250 and few if any graduate students; classes are usually small, from 15 to upwards of 30 students; the faculty developer may operate with little or no 
budget, space, or support staff; and most activities and conversations about teaching take place face to face. Of these various traits, overall culture is key, especially the value placed on teaching.

Here we aim to capture and convey the central issues coalescing around the professionalization of teaching and learning activities and the work of faculty developers at small colleges. While this descriptive review draws direct comparisons to other types of institutions, particularly large research and comprehensive universities that serve as the norm for our profession's faculty development practices, its main purpose is to address the distinctive characteristics of professional development at liberal arts colleges and its connection to the type of education these institutions typically offer. Toward this end, we address four key issues: the characteristics and traditions related to teaching and learning in these institutional settings; the models and structures for teaching and learning programs at such colleges; the distinctive components of successful faculty development at such institutions; and the future trends and issues small college faculty developers will likely need to address through their programming and as they continue to shape the future of our profession.

Perhaps more so at liberal arts colleges than anywhere else in American higher education, exceptional teaching is explicitly sought, expected, and valued. But often new faculty at these institutions quickly realize that they lack the pedagogical training necessary to meet these expectations. Authors elsewhere have noted that faculty responsibilities and cultures at liberal arts and small residential colleges differ markedly from those at the research universities in which most of us were trained (Gibson, 1992). Even high-quality, discipline-specific training does not prepare us for the scope and variety of demands we face in small college faculty roles (Reder \& Gallagher, 2007; Rice, Sorcinelli, \& Austin, 2000).

According to the most recent national data from the Higher Education Research Institute (HERI) (Lindholm, Szelény, Hurtado, \& Korn, 2005), the percentage of full-time undergraduate faculty with a major interest in teaching varies by institution type: $17 \%$ for public and private university faculty and $35 \%$ for public and private four-year colleges. Yet ironically, the most established faculty support at four-year colleges is for disciplinary scholarship, especially as most of these institutions offer sabbaticals, many pre-tenure, which are usually geared toward supporting research agendas. Almost universally, colleges and universities have strong systems for funding faculty research and disciplinary conference presentations. They view scholarship as a public enterprise that can and should be replicated, extended, and critiqued by peers.

Even at colleges that claim to value teaching, faculty members do not expect to engage in such communal activity in regard to teaching. As Reder and 
Gallagher (2007) argue, small colleges that claim to emphasize teaching must put resources behind "promoting the critical discussion of teaching"; "such schools can no longer get away with giving mere lip service to valuing teaching" (p. 339). At most small institutions, unlike many large universities, teaching is assumed to be important, and this assumption may allow such schools (or faculty) to get away with avoiding teaching issues, relying on the false logic of "We all value teaching; that is why we are here; therefore, we must all be good at it." The increased participation by small college faculty developers in POD and the growing number of small colleges initiating formal faculty development programs and teaching and learning centers reveal growing recognition of the need to formally support continuing pedagogical education. Evidence also suggests that faculty at these institutions are taking advantage of this emerging support. When asked whether they had participated in a faculty development program in the past two years, $79 \%$ of the four-year college faculty responded that they had, compared to only $49 \%$ of the university faculty, according to the HERI data (Lindholm et al., 2005). Yet both types of faculty overwhelmingly maintain the personal goal of being a good teacher $(97 \%$ at universities and $98 \%$ at four-year institutions) (Lindholm et al., 2005).

In spite of their deep interest in teaching, faculty at smaller colleges report experiencing greater stress from the demands of their teaching loads than do their colleagues at larger universities (Lindholm et al., 2005). They also report spending more time teaching and preparing for teaching, including grading, and they are less satisfied with their teaching loads.

Given the differing teaching expectations and experiences between faculty at small colleges and larger universities, it is no surprise that the nature of faculty development varies by institutional type. According to national survey data (Sorcinelli et al., 2006), faculty developers at liberal arts colleges focus more on creating or sustaining cultures of teaching excellence and advancing initiatives in teaching and learning than do their colleagues at research/doctoral institutions and community colleges. Both groups are more concerned about providing support to faculty having difficulty. The researchers speculate that this finding reflects the continued emphasis on excellent teaching in the liberal arts even while many smaller schools are emphasizing scholarly production. In some ways, this dual focus suits the newer faculty cohorts, which value active scholarship (Stimpert, 2004).

This research suggests that, beyond offering formal programs to support effective teaching, faculty developers need to be aware of the teaching issues that create stress for their faculty. Teaching effectively at a small college, and therefore successful faculty development, is not just about pedagogy; it requires attending to the tenuous and often daunting balance 
between teaching and scholarly pursuits. Teaching and scholarly expectations at small schools, especially with the growing emphasis on facultymentored student research, have important implications for creating and funding faculty development programs that address concerns beyond the confines of the traditional classroom.

\section{Models and Structures of Faculty Development Programs}

Sorcinelli et al.'s (2006) data indicate a notable increase during the past 15 years in the number of centralized faculty development units with dedicated staff, when compared to the less formal efforts organized by a single administrator or advisory committee. This trend toward formal structures is particularly evident among research and doctoral institutions, where $72 \%$ report a centralized unit dedicated to faculty development. Liberal arts colleges report the smallest percentage of centralized structures (24\%) and the largest percentage of "one-person" programs. Small colleges also report the highest reliance on advisory boards.

While larger university centers usually employ a full-time director and often full-time professional and clerical staff, no predominant administrative structure exists for smaller colleges. Faculty development-where faculty engage in conversations about teaching and learning in particular-can and does happen anywhere. But when these diffuse and sometimes haphazard forays become centralized, it is often less about a physical space for faculty development than about one person or a group of persons who coordinate and advance the efforts. Whether part of the portfolio of an associate dean, the purview of a faculty development committee, or as the job of a particular individual (frequently with an advisory board), the "center" is often, unlike in our university brethren, a metaphorical one. Indeed, several of the more prominent small college faculty development programs/centers have no physical space. Peter Frederick has long argued that at a small college, having physical space is not necessary and can in fact deter a program's success. We do believe that having a center, even if it is so only in name, gives a program a place and identity on campus, especially on a campus where centers have status (P. Frederick, personal communication, November 26, 2004). A center is the "place" where things happen, where things are embedded and made visible.

Faculty development models and administrative responsibilities vary widely among liberal arts and smaller institutions, and each may be very effective for its campus culture. A number of liberal arts colleges dedicate physical space for centers and are led by a director selected from among the tenured faculty (e.g., Colorado College, St. Lawrence University, and Whitman Col- 
lege). Others have center directors with offices but no dedicated program space (e.g., Connecticut College and Muhlenberg College), while a few are managed out of the dean's office (e.g., Allegheny College and Southwestern University).

Faculty developers often emerge from the tenure-track faculty ranks (Mullinix \& Chism, 2005), but at smaller colleges, the job is seldom full-time with a dedicated staff. Although these individuals consider faculty status critical to their credibility (Mullinix \& Chism, 2005), their continuing to teach, advise students, publish in their disciplines, and serve on committees creates a challenging "many hats syndrome." In an informal poll of 16 small college faculty developers at a recent 2006 POD small college business meeting, 10 out of $16(63 \%)$ reported time as their most pressing or only challenge. Most of the time pressures derived from the multiple roles directors fulfill on their campuses, followed by the demands of the faculty for whom they design and implement programming.

Not only are small college faculty developers pressed to find time to serve their faculty, but their names often become synonymous with faculty development. The strong identification of one person to this role is more than a function of campus size; it also reflects the nascent stage of faculty development at liberal arts colleges. These two interdependent issues, person-program identity and first-generation developers, present a challenge to the continuity and sustainability of faculty development work at a small college.

Sustainability may be the single most critical issue facing small college faculty development. Because at many small colleges no formal administrative structure for faculty development exists—such as a dedicated staff line that needs to be filled and a predictable, continuing budget to support activitiesongoing programming often sits precariously between success and oblivion. For example, when faculty development is centralized under an individual dean or faculty member, that person's sabbatical or return to the faculty may jeopardize all that he or she accomplished. Faculty development committees may also face the same challenge when the chair rotates and members move on and off, bringing on new people with little knowledge of faculty development. In addition, the faculty development coordinator must single-handedly offer the full range of services, some of which would be distributed to other staff at larger institutions. So the faculty developer running a "single-person" program is under pressure to have command of the ever growing faculty development field.

Because we find ourselves among the first generation of faculty tapped to lead faculty development programs/centers at small colleges, and because this position requires reeducating and retooling beyond our disciplines, many of 
us lack local mentors or colleagues. On larger campuses with multiperson centers where faculty development has thrived for years, mentors are more readily available. Therefore, the emerging national network of small college faculty developers becomes a significant and often sole source of critical and creative professional feedback. Perhaps equally important, the practitioners at larger institutions who wish to mentor those of us at smaller colleges need to understand the differences and similarities between small college and large university faculty development work.

\section{Features of Successful Small College Faculty Development Work}

Peter Frederick, a long-time advocate and original organizer of small college faculty development work and the founder of Carleton College's Learning and Teaching Center, recommends that small college faculty developers look for programming opportunities wherever faculty (or faculty and students) routinely come together within their particular campus culture. Specifically, he suggests embedding programs in staff planning meetings, in core and capstone courses, and in team-taught introductory courses. In busy faculty lives where going to a workshop, however inviting, is just one more thing on an overflowing plate, these already established settings are where the best, most practical, and most immediately useful holistic "development" can take place (P. Frederick, personal communication, November 26, 2004).

In spite of the time constraints of those directing faculty development programs at small colleges, the small college publication record in the past four volumes of To Improve the Academy (2004-2007) shows that successful programs do get implemented on small college campuses. Whether focusing on mentoring new faculty (Fayne \& Ortquist-Ahrens, 2006; Reder \& Gallagher, 2007) or promoting innovative pedagogies (Blumberg, 2004; Mooney, Fordham, \& Lehr, 2005) or creating opportunities for ongoing special-topic conversations (Holmgren, 2005; Jones, 2005), these programs described in To Improve the Academy share several common elements. First and perhaps most importantly, faculty participation was voluntary; no faculty members were remanded or cajoled into attending a single meeting. Second, in five of the six programs just cited, people committed to a series of meetings with the same community of colleagues, even if the designated topics changed. In addition, leaders established regular meeting times, provided common readings, and guided participants in ways to provide regular feedback to one another. Finally, almost all of the programs dedicated time to participant reflection on 
the learning process and outcomes of their participation in the faculty development program. The differences among these programs are relatively superficial-for example, at least one offered stipends for faculty participation but most did not; at least one was almost entirely electronic; and at least one had fewer than 6 continuing participants while another had more than 15 .

Success or failure of faculty development programs on small college campuses has a unique economy of scale, and it is one that we encourage colleagues to consider as they prioritize their program planning. On a small college campus, a workshop that attracts 30 faculty members may reach almost $20 \%$ of the total faculty at once and could be a transformative experience for the faculty, exposing a significant proportion of the faculty to something new. However, if the workshop is not well received or perceived as useful, $20 \%$ of the faculty are potentially alienated. On a small college campus where the entire faculty knows each other by name, there is also a multiplier effect: If each of those 30 faculty speaks with one other person about his or her experience, whether good or bad, then suddenly $40 \%$ of the faculty can be impacted by a single event. In addition, with such a small faculty, where there are a limited number of people to attend seemingly unlimited numbers of campus events, "overprogramming" is always a threat. Colleagues at other small schools have corroborated this problem: With so much going on (e.g., special speakers, job search talks), we often bring to campus well-known (and sometimes expensive) speakers/facilitators, and fewer than 12 people end up coming-even after a lot of effort promoting the event. The faculty are not indifferent, just busy. So we have to plan thoughtfully, develop creative collaborations with other offices and divisions, and diligently use the campus master calendar.

Describing a single faculty development workshop or a semester-long program as successful is certainly a function of the local campus and faculty culture, but in our collective (albeit time-limited) experience in program planning and implementation, we offer seven recommendations to colleagues just starting out as faculty development coordinators or directors on small college campuses (Reder \& Mooney, 2004):

- Create an advisory board and include a few "unusual suspects."

- Make your program/center a place of excellence.

- Start with one program and do it very well.

- Use the talent pool on your own campus. 
- Generate grassroots interest in your programs before announcing them to the faculty.

- Continue to attend conferences in higher education (POD, Association of American Colleges and Universities, etc.).

- Provide refreshments to acknowledge that you value colleagues' time.

As the momentum behind faculty development programs at small colleges continues to grow, not only will this list expand, but so too will the number of contributors to it.

\section{Future Trends in Small College Faculty Development}

The changing and multicultural demographics of college students continue to increase new instructional opportunities for and demands on faculty preparation time and workload, and the support faculty developers provide must be responsive to these evolving realities (Rice, 2006; Sorcinelli et al., 2006). The digital literacy of college students and their daily exposure, applications, and saturation levels "lead to pedagogical challenges... as (faculty) search for the means to teach Net generation students in a manner that capitalizes on the group's technology-driven lifestyle and fosters quality liberal learning" (Carey, 2006, p. 3; see also Oblinger \& Oblinger, 2005). As instructional roles and classroom settings continue to expand and change, the need for faculty to learn new skills and to teach differently will require increased, not compromised, support (Lieberman \& Guskin, 2003). Whether differences in the future work for small and large institutions are more about scale and scope than about the nature of the educational issues remains to be seen.

Despite some agreement, there is no clear consensus among faculty developers on the direction of our professional foci over the next 10 years, nor is there tremendous overlap in perceptions of how the field should change and how it is likely to change (Sorcinelli et al., 2006). Undoubtedly, faculty development will respond to the continued emphasis on outcomes assessment generated by regional accreditation agencies and more recently by the Spellings Commission report and higher education's responses to it (U.S. Department of Education, 2006). In addition, the field will address two other engines of change: the role of technology in teaching and learning and the nature of the faculty workforce itself. Even on small college campuses, the impact of technology and new faculty cohorts and appointment types will likely impact faculty development work. 


\section{The Role of Technology at Small Colleges}

Recent national survey data indicate that faculty developers are well aware of the force behind the movement to integrate technology into teaching, learning, and many other dimensions of higher education, but they do not uncritically embrace technology as a central focus for future faculty development efforts (Sorcinelli et al., 2006). "The electronic learning environment requires thinking differently about delivery, content, and student feedback. It is critical that the academy focuses not only on the importance of technological delivery, but also on the pedagogy involved in this process" (Lieberman \& Guskin, 2003 , p. 265). Perhaps because technology leaders at small colleges are at a disadvantage in terms of economies of scale, they may feel as if they are always playing catch-up with their peers at larger institutions. Rather than look merely at the current role of technology at small colleges (e.g., see Smallen \& Leach, 2004), studies need to explore the ideal roles for instructional technology by framing the issue squarely within the literature about student learning and teaching with technology (Chickering \& Ehrmann, 1996; Ehrmann, n.d.), as well as within the context of a small college focused on teaching. In various national forums, academic leaders from liberal arts institutions have raised legitimate questions and sometimes conflicting viewpoints about the role that technology can and should play on their campuses, particularly in relation to student learning. This lack of consensus represents a common disparity in perceptions among liberal arts faculty and among faculty developers. What faculty development programs need to do, however, is facilitate the discussions around the role of technology in student learning.

Liberal arts and other small institutions that emphasize small classes and face-to-face interaction are less likely to be spending faculty development time and resources on online course design and implementation, another place where the role of technology at small colleges differs greatly from that at larger institutions. Faculty developers should raise and address questions like these: What role does and should instructional technology play in the distinctive setting of small residential liberal arts colleges? To what degree does technology play into the strengths that small liberal arts colleges have to offer: intimate classes, a great deal of student and faculty contact, and the opportunity for one-on-one individualized study and research? What evidence indicates that teaching with technology plays a central or transformative role in the learning process? Does the faculty member teaching a 12-person seminar at a liberal arts college need technology in the same ways that a peer teaching a 300-student lecture course at a larger institution might? At both small and large institutions, technology does have the potential to increase student learning, but the distinct issues related to technology and the small college have yet to be studied systematically. 


\section{Whe Facully Workforce at Small Colleges}

Planning future faculty development programming in educational technologies extends beyond training faculty in new classroom pedagogies and applications. Advances in educational technologies lead to the "unbundling of the faculty role" (Rice, 2007, p. 14), and when coupled with the proliferation of nontenure-track faculty appointments, the implications for faculty developers are challenging. Increasingly, faculty developers may be positioned to support instructors who come to teaching with nonacademic backgrounds and assume nontraditional faculty roles in the academy. Although small colleges may not experience the changing nature of faculty appointments as much as larger universities, no institution type is immune from the need to consider how to support and respond to the changing demographics and workload issues of future faculty members.

According to the most recent HERI data, at least $43 \%$ of responding faculty perceive mentoring new faculty as among the highest priorities of their institutions, regardless of size (Lindholm et al., 2005). As the small college session topics and attendance at the past three POD conferences attest, small college faculty developers are very interested in implementing constructive new faculty orientation and mentoring programs on their campuses. Far less is known or widely discussed about faculty needs and issues at other points in their careers.

The professional issues and transitions of faculty in post-probationary years are currently ill defined but warrant attention in order for institutions to benefit from the experience of mid-career faculty (Baldwin \& Chang, 2006). In a recent study on support for mid-career faculty, Baldwin and Chang (2006) discovered that while colleges and universities are beginning to pay attention to faculty in this career phase, few programs approach their support or programming in coordinated or comprehensive ways. Connecting faculty across generations may be a challenge worth pursuing as senior and junior colleagues have much to gain from each other. Certainly, early-career faculty might benefit from the institutional wisdom a senior colleague might offer about issues ranging from a college's priorities to a deeper appreciation of its students (Rice et al., 2000). On smaller campuses where administrative leadership is less layered and often harvested from faculty ranks, it is critical for more senior colleagues to mentor recently tenured and mid-career faculty to help prepare them for such leadership positions. One constructive byproduct of such mentoring is that the sincere solicitation of senior colleagues' pragmatic advice may encourage detached faculty to reinvest in the institution even as they grow closer to retirement. Creating model programs that include and draw on the experiences of senior faculty to support mid-career faculty is 
one area where small colleges can make significant contributions. Especially at small colleges, where senior administrators often rise from the faculty ranks, the need to develop the next generation of leadership is overdue for sustained and coherent attention.

\section{Charting Our Course for the Future of Small College Teaching and Learning}

What may distinguish small colleges, particularly residential liberal arts colleges, from their larger institutional counterparts is the creation and support of a community of learners. In fact, we believe this mission is central to faculty development programs at small institutions. One reason we employ and favor the term center for teaching and learning to describe our work is the idea of a "center," a component that is central for the day-to-day operations of our colleges. Even if a center has no physical space, our programs provide a metaphorical center for the many activities related to teaching and learning that occur daily across our campuses. Our programming serves as a crossroads of sorts, where issues as diverse as support for early-career faculty, curriculum design, general education, learning outcomes and assessment, information fluency, and technology all come together under the guiding principle of supporting faculty teaching to enhance student learning.

According to Sorcinelli et al.'s (2006) data, faculty developers at liberal arts institutions believe that their efforts should continue to be planned and directed by the faculty in response to the faculty. Faculty development programs are distinctively situated at small colleges to play a neutral role focused on improving student learning rather than advancing any partisan cause. At Connecticut College, for example, the president asked the Center for Teaching and Learning (CTL) to run a series of discussions focused on diversity in the curriculum; the dean of the faculty and the faculty curriculum committee requested that the CTL kick-start the revision of the general education program by hosting a series of discussions and dinners; and the main faculty governance committee asked the CTL to design a new program to connect entering faculty with their more senior, tenured colleagues across the disciplines. Similarly, since its inception in 2001, the Center for Teaching and Learning at St. Lawrence University has engaged in a wide range of programming and initiatives and strives to be responsive to emerging curricular issues on campus. For example, in its short history, the annual end-of-the-year May Faculty College has evolved into a strategic planning conference that draws together a significant number of faculty from across the disciplines to discuss the theory and 
practice of teaching and learning in liberal education. A well-established and productive partnership with the educational technologies staff has generated annual technology programs in August and January and most recently led to the co-development of a best practices web site for faculty to share their pedagogical innovations.

The programming goals of all of these initiatives may seem diverse, but they all are ultimately focused on improving student learning, even those seemingly focused on issues of improving faculty experiences or changing curricula. They go about advancing these goals by creating opportunities for faculty to come together in a public setting to share their ideas about curriculum, classroom teaching, and student learning. While the primary faculty development goals may not differ between larger, more research-oriented universities and smaller, mostly residential colleges, we believe the teaching and learning expectations and faculty development work at these small colleges are sufficiently unique to warrant continued exploration, discussion, and collaboration among faculty development colleagues across the profession.

\section{References}

Baldwin, R. G., \& Chang, D. A. (2006, Fall). Reinforcing our "keystone" faculty: Strategies to support faculty in the middle years of academic life. Liberal Education, 92(4), 28-36.

Blumberg, P. (2004). Documenting the educational innovations of faculty: A win-win situation for faculty and the faculty development center. In C. M. Wehlburg \& S. Chadwick-Blossey (Eds.), To improve the academy: Vol. 22. Resources for faculty, instructional, and organizational development (pp. 41-51). Bolton, MA: Anker.

Brinko, K. T., Atkins, S. S., \& Miller, M. E. (2005). Looking at ourselves: The quality of life of faculty development professionals. In S. Chadwick-Blossey \& D. R. Robertson (Eds.), To improve the academy: Vol. 23. Resources for faculty, instructional, and organizational development (pp. 93-110). Bolton, MA: Anker.

Carey, S. J. (2006, Fall). From the editor. Peer Review: Learning \& Technology, 8(4), 3.

Chickering, A., \& Ehrmann, S. C. (1996, October). Implementing the seven principles: Technology as lever. AAHE Bulletin, 49(2). Retrieved May 17, 2007, from www.titgroup.org/programs/seven.html

Ehrmann, S. C. (n.d.). Asking the right question: What does research tell us about technology and higher learning? Retrieved May 17, 2007, from www.tltgroup.org/ resources/Flashlight/AskingRightQuestion.htm 
Fayne, H., \& Ortquist-Ahrens, L. (2006). Learning communities for first-year faculty: Transition, acculturation, and transformation. In S. Chadwick-Blossey \& D. R. Robertson (Eds.), To improve the academy: Vol. 24. Resources for faculty, instructional, and organizational development (pp. 277-290). Bolton, MA: Anker.

Frantz, A. C., Beebe, S. A., Horvath, V. S., Canales, J., \& Swee, D. E. (2005). The roles of teaching and learning centers. In S. Chadwick-Blossey \& D. R. Robertson (Eds.), To improve the academy: Vol. 23. Resources for faculty, instructional, and organizational development (pp. 72-90). Bolton, MA: Anker.

Gibson, G. W. (1992). Good start: A guidebook for new faculty in liberal arts colleges. Bolton, MA: Anker.

Holmgren, R. A. (2005). Teaching partners: Improving teaching and learning by cultivating a community of practice. In S. Chadwick-Blossey \& D. R. Robertson (Eds.), To improve the academy: Vol. 23. Resources for faculty, instructional, and organizational development (pp. 211-219). Bolton, MA: Anker.

Jones, L. F. (2005). Exploring the inner landscape of teaching: A program for faculty renewal. In S. Chadwick-Blossey \& D. R. Robertson (Eds.), To improve the academy: Vol. 23. Resources for faculty, instructional, and organizational development (pp. 130-143). Bolton, MA: Anker.

Lieberman, D. A., \& Guskin, A. E. (2003). The essential role of faculty development in new higher education models. In C. M. Wehlburg \& S. Chadwick-Blossey (Eds.), To improve the academy: Vol. 21. Resources for faculty, instructional, and organizational development (pp. 257-272). Bolton, MA: Anker.

Lindholm, J. A., Szelény, K., Hurtado, S., \& Korn, W. S. (2005). The American college teacher: National norms for the 2004-2005 HERI faculty survey. Los Angeles, CA: University of California-Los Angeles, Higher Education Research Institute.

Mooney, K. M., Fordham, T., \& Lehr, V. D. (2005). A faculty development program to promote engaged classroom dialogue: The Oral Communication Institute. In S. Chadwick-Blossey \& D. R. Robertson (Eds.), To improve the academy: Vol. 23. Resources for faculty, instructional, and organizational development (pp. 220-235). Bolton, MA: Anker.

Mooney, K., Reder, M., \& Holmgren, R. (2005, January). Transforming teaching cultures: The need for teaching and learning programs at liberal arts colleges. Paper presented at the annual meeting of the Association of American Colleges and Universities, San Francisco, CA.

Mullinix, B. B., \& Chism, N. V. N. (2005, October). The faculty status of faculty developers: A collaborative construction and collective explorations. Paper presented at the 30th annual meeting of the Professional and Organizational Development Network in Higher Education, Milwaukee, WI. 
Oblinger, D. G., \& Oblinger, J. L. (Eds.). (2005). Educating the net generation. Boulder, CO: Educause.

Professional and Organizational Development Network in Higher Education. (2006). $P O D$ institutional membership by Carnegie classification. Internal POD Network Document.

Reder, M., \& Gallagher, E. V. (2007). Transforming a teaching culture through peer mentoring: Connecticut College's Johnson Teaching Seminar for Incoming Faculty. In D. R. Robertson \& L. B. Nilson (Eds.), To improve the academy: Vol. 25. Resources for faculty, instructional, and organizational development (pp. 327-344). Bolton, MA: Anker.

Reder, M., \& Mooney, K. (2004, November). Getting started in small college faculty development. Roundtable at the 29th annual meeting of the Professional and Organizational Development Network in Higher Education, Montreal, Canada.

Rice, R. E. (2006, Fall). From Athens and Berlin to LA: Faculty work and the new academy. Liberal Education, 92(4), 6-13.

Rice, R. E. (2007). It all started in the Sixties: Movements for change across the decades-A personal journey. In D. R. Robertson \& L. B. Nilson (Eds.), To improve the academy: Vol. 25. Resources for faculty, instructional, and organizational development (pp. 3-17). Bolton, MA: Anker.

Rice, R. E., Sorcinelli, M. D., \& Austin, A. E. (2000). Heeding new voices: Academic careers for a new generation. Washington, DC: American Association for Higher Education.

Smallen, D., \& Leach, K. (2004). Information technology benchmarks: A practical guide for college and university presidents. Washington, DC: Council of Independent Colleges.

Sorcinelli, M. D., Austin, A. E., Eddy, P. L., \& Beach, A. L. (2006). Creating the future of faculty development: Learning from the past, understanding the present. Bolton, MA: Anker.

Stimpert, J. L. (2004, July/August). Turbulent times: Four issues facing liberal arts colleges. Change, 36(4), 42-49.

U.S. Department of Education. (2006). A test of leadership: Charting the future of U.S. higher education. Washington, DC: Author. 